\title{
Práticas documentais e estética na tradição de 'separar o joio do trigo'
}

Kati Eliana Caetano

\section{Resumo}

Centrado na discussão da imagem visual, o texto discorre sobre os seus usos com função informativa e os desdobramentos gerados inicialmente por uma oposição estabelecida no domínio das mídias entre documentação e estética. Com base no postulado de que as imagens podem constituir elemento importante para uma estética da comunicação, 0 trabalho tem como ponto de partida o jornalismo impresso e se estende a certas formas colaborativas do ciberespaço na produção de matérias visuais, redimensionando a afirmativa de uma estetização das mídias, amparada, nesses contextos, em seus artifícios técnicos e dimensão afetiva das interações. Palavras-chave

Documentarismo. Estética. Efeito de realidade. Políticas da imagem. Imagem informativa.

\section{Kati Eliana Caetano | kati.caetano@utp.br}

\section{Imagens em êxodo}

A imagem documental envolve vários eixos de discussão, que vão desde 0 questionamento de sua existência ou especificidade até a polêmica mais recente de que, na era do virtual, com a síntese numérica, inexiste um referente. Um dado em particular cruza a maior parte desses debates, que indaga sobre as condições para uma comunicação estética fundada em propostas documentais. Radicalizados originalmente no velho binômio beleza-verdade, os embates foram ganhando contornos mais fluidos, mas não deixam de ser instigantes para tratar da questão estética da comunicação.

Uma vez registrada pela máquina como resultado de uma captura direta do real, a imagem agrega ao seu estatuto técnico um valor ideológico: adquire 0 vinco da objetividade e, em última instância, da "verdade". Com esse atributo, torna-se um valor para as mídias, pelo efeito de credibilidade que acarreta e de atração da audiência para a publicidade. Revestida dessa importância, a fotografia, primeira imagem técnica, revela-se, já nas primeiras décadas 
do século XX, elemento fundamental para a comunicação visual. A imagem com propósito informativo nasce, portanto, no seio da própria mídia, inicialmente no jornalismo impresso, em seguida nos outros meios de comunicação, quando é redimensionada a partir de novos paradigmas tecnológicos. Sua formalização técnica não se processa sem consequências sociais e econômicas, pois passa a configurar 0 modo adequado de representar a realidade, sobretudo em produção massiva, do que deriva o seu valor de mercado. "El aprendizaje de la mirada como documental, como contrato de credibilidad, exige una relación de identidad con la tecnología y comporta la experiencia de la mediación: estamos en el mundo a través de su representación" (LEDO, 1998, p. 13).

Do grau de aceitação e exploração da fotografia como evidência vai depender seu funcionamento dentro e fora das mídias, considerando-se nessa fase inicial o jornalismo diário e a revista como os seus espaços de consolidação. Escandem-se, assim, práticas fotográficas que agenciam padrões tecno-estéticos considerados mais propícios ao fotojornalismo, baseados na busca da notícia e na ideia de atualidade, e outras propostas documentais. Boa parte delas está voltada ao que se chama documentação social, em que as escolhas técnicas implicam regimes de sentido a serem compartilhados pelos destinatários. Embora consagrada entre os fotógrafos, essa distinção não é categórica; revela neutralizações e êxodos, como diria Margarita Ledo, concebendo este conceito como modos de existir entre territórios (1998, p. 18). Mesmo no âmbito do documentarismo autoral, as práticas ativam tensões entre captar o real "tal qual ele é" - do que derivam recursos de pretensa neutralidade diante do fotografado - ou exprimi-lo em sua essência conceitual, segundo modos de operar singulares que visam a desestabilizar a noção de objetividade. ${ }^{1} 0$ fato é que, em sua manifestação hegemônica, as formas de representação visual destinadas a nos fornecer um parecer do mundo permeiam as diferentes mídias com feição similar, a despeito das potencialidades técnicas para converter os discursos imagéticos em configurações promotoras de releituras tanto do mundo quanto do verbal.

A distinção entre ambas costuma ser marcada pela ausência de controle do autor sobre seu próprio trabalho, atendendo a uma pauta, sob pressão do tempo e sem direitos comerciais no que concerne à imagem fotojornalística; de livre escolha, execução durativa num tempo desacelerado e domínio sobre seu produto

Embora a fotografia de jornalismo, dentre as subdivisões da fotografia, englobe o fotodocumentarismo, há uma distinção comumente estabelecida entre as fotos de notícias, mais comuns nos cotidianos, e aquelas resultantes de projetos autorais, normalmente destinadas a circulação mais restrita - em galerias, exposições, publicação em livros e a eventos específicos da foto realidade (BAEZA, 2001, p. 41; FREUND, 2002). Por outro lado, como afirma Sousa, fotografias que não são produzidas para circular na mídia, podem-se tornar fotografias jornalísticas, pela ancoragem que manifestam com os fatos conjunturais (2004, p. 11). Não se trata, porém, de abordá-las como bifurcações e sim como ocorrências submetidas a diversos tipos de flutuações. 
no caso da fotografia documental (BAEZA, 2001). A história do fotojornalismo ocidental (SOUSA, 2000) e das manifestações de fotodocumentarismo (LEDO, 1998) é reveladora dos diferentes trajetos por que passaram essas duas modalidades de fotografias, bem como de sua situação atual em face da propalada crise do jornalismo e da hegemonia da imagem virtual. Para a análise que ora empreendemos, interessa considerá-las, de início, em suas distintas condições como duas manifestações da imagem informativa, tanto do ponto de vista de suas contingências comerciais, quanto no tocante aos padrões estéticos assumidos, por abordálas como reveladoras de diferentes políticas de figuração visual.

A abordagem estética da imagem, como uma particularidade indissociada da estética da comunicação, foi incrementada com o postulado de uma estetização generalizada das mídias, em relação à qual alguns discursos necessitavam ser diferenciados. Mesmo diante da assertiva de vários de seus cultores negando-lhe qualquer traço de esteticidade, a imagem documental não fica isenta desse debate, principalmente quando considerada em sua função político-social. Retomemos alguns princípios fundamentais dessas reflexões.

\section{A eficácia documental como solução estética e não como representação do real}

Na tradição dos estudos estruturais, considera-se que a função estética resulta da íntima relação entre o plano material das linguagens - chamado de plano da expressão - e o plano do conteúdo. Embora tal divisão seja meramente metodológica, ela tem servido de base para diferenciar tratamentos voltados enfaticamente seja para veicular sentidos, do que deriva um destinatário empenhado em processos de decodificação, seja para pôr em relevo os recursos fônicos, plásticos, rítmicos de uma certa materialidade linguageira, às vezes agenciados em meros exercícios de virtuose. 0 laço de analogia entre ambos os planos, ao contrário, definiria seu uso estético, na medida em que os componentes materiais não seriam instrumentos a serviço de conteúdos, mas formalizações capazes de suscitar a sensação da presença dos sentidos, estes moduladores de encontros entre os sujeitos na relação com as coisas do mundo. Em outros termos: não haveria, dessa perspectiva, sentidos prontos, pois eles resultam dos compartilhamentos em ato. Em princípio, a constituição estética encontraria na arte, mas não só nela, a possibilidade exponencial de experimentações desestabilizadoras, porque esse é o espaço de explosão do automatismo dos valores e das práticas.

Na esteira dessa mesma tradição, concernente ao domínio das representações visuais, a composição plástica de uma imagem seria tanto mais merecedora de atenção quanto mais estreita fosse sua vinculação com o conteúdo evocado. A função estética resultaria, assim, de uma espécie de atalho entre a forma da expressão e a do conteúdo, como diria A.-J. Greimas, e estaria 
presente não só nos grandes arroubos artísticos (as "fraturas estéticas"), mas em situações da cotidianidade capazes de romper com a monotonia da vida (as "escapatórias"). Em sua obra De l'imperfection (1987, p. 71-98), Greimas enfatiza o caráter estético de certas práticas, constituídas às vezes em hábitos, mostrando a importância dos aspectos estésicos para a constituição dos sentidos em situação e expondo com toda a evidência o papel da fenomenologia de Husserl e Merleau-Ponty na elaboração de seu projeto semiótico. 0 atalho entre 0 plano da expressão e do conteúdo, portanto, não diz respeito à imediatez do ato de reconhecimento de uma figura, mas à sua força expressiva, passível de colocar em presença, por determinantes cognitivos e sensíveis, os sujeitos de uma enunciação (visual, sonora, etc.). Para acionar tais regimes de presença, o plano da expressão não pode simplesmente reduzir-se a "veículo" de uma ideia; ao contrário, deve formalizá-la a ponto de conter na sua "carne matérica" a impressão de presença daquilo que traduz e, por meio dela, agir sobre o corpo próprio inscrevendo-o no modo do sensível nas relações comunicacionais. Como conceber esse fenômeno e em que medida seria diferente, por exemplo, o efeito de presença obtido numa relação estética e a saturação de apelos estésicos das mídias, muitas vezes redundando em efeitos de anestesia dos sentidos?

Embora preconize na função estética 0 ato de re-ver o mundo, a semiótica não a esclarece em relação ao ato compreensivo. Para desenvolver o raciocínio que parece sustentar, mesmo que involuntariamente, essa ideia de um encontro transformador inerente à estética da comunicação, recorremos ao pensamento de Heidegger (HEIDEGGER, 2008; VATTIMO, 1989).

A presença não deve ser abordada como pura contemplação, que coloque em campos distintos um sujeito e um objeto; na acepção heideggeriana, ela envolve uma situação afetiva como "uma espécie de primeira 'preensão' global do mundo que, de alguma maneira, funda a própria compreensão" (VATTIM0, 1989, p. 38). Essa valência afetiva é condição fundamental da compreensão do mundo tanto na perspectiva de uma totalidade prévia de significados, segundo a opinião comum (uma vez que 0 ser está no mundo junto de outros, de "ser-com", com quem funda suas opiniões comuns na base de um "se" anônimo), quanto na condição de elemento fundamental de uma relação mais complexa, direta, com as coisas, quando o sujeito (como "estar-aî", p. 27) se realiza plenamente como projeto ou "poder ser". 0 que fazem certos discursos é construírem-se de tal modo que sua presença evoque essa experiência originária com as coisas. Por outro lado, esse encontro direto só se faz mediante os "signos" e sob a forma de sua inclusão dentro do próprio projeto de existência (p. 45), uma vez que, na perspectiva de Heidegger, o ser encontra-se em constitutividade de dupla mão com o mundo, sendo definido em termos históricos. 
0 componente afetivo - e sua encarnação estésica - está na base do ato compreensivo, que não deve, por conseguinte, ser confundido com a ideia da recepção de mensagens da teoria da informação. Deriva desse postulado a ilação de que 0 caráter transformador das imagens estéticas preconizadas pela tradição estrutural só se exercerá quando a incompletude de sua natureza representativa constituir 0 dado primeiro, ou seja, quando a sua condição simbólica de importante papel nas relações intersubjetivas para a constituição do sentido for considerada. Nesse aspecto, é possível aprofundar a posição de Greimas com base no postulado de Heidegger. Na condição de formas simbólicas, as imagens não manifestam uma realidade previamente dada e não se destinam, apenas, a veicular significados decifráveis; podem, sim, integrar experiências no mundo para as quais funcionam como elementos de vivificação dos sentidos, compartilhados em ato, e, portanto, em constante vir-a-ser. Por isso, a desestabilização de seus usos convencionais, explodindo as aparências cristalizadas, favorecem, em princípio, os movimentos reflexivos. Cuidemos, porém, para que tal afirmação não seja compreendida dentro de estreitos limites. A desestabilização do caráter naturalista das imagens tem como recurso extremo, do ponto de vista formal, a ruptura figurativa em direção a imagens inusitadas ou abstratas, tendência, aliás, hegemônica nas experimentações artísticas. Ele não deve, porém, ser apreendido apenas dessa perspectiva, que é a que parece subsidiar as reiteradas conclusões sobre 0 caráter desconstrutor das poéticas digitais, assim como a oposição entre artístico e documental. Quando se fala da imagem informativa, inclusive, torna-se um pressuposto, senão a figuratividade, pelo menos uma certa figuralidade (considerada pela rarefação de traços identificadores do referente, expresso em sua minimalidade). Desse modo, as instabilidades no âmbito do documental requerem como condição fundante a figuratividade, que pode, no entanto, servir de porta de acesso ao seu próprio questionamento, contando, entre outros recursos, com a revelação do discurso como um ponto de vista. Com isso, evidencia-se o caráter ilusório de seu aspecto natural, num lance de negação oblíqua da função referencial, conforme assevera Jean-Marie Floch a partir da instigante foto "Olhar Oblíquo" de Robert Doisneau (apud FLOCH, 1986, p. 43-48). É no âmbito do agenciamento das imagens, em dinâmicas de encenação ou de representação e de sua organização plástica ${ }^{2}$, que a referencialidade pode vir a ser neutralizada em proveito de regimes de interação mais inusitados. Queremos afirmar, em suma, que o estético é condição sine qua non da eficácia documental, assim como de qualquer tipo de discurso, na qualidade de fenômeno propício à compreensão como 
experiência sensível. Melhor dizendo, o estético está na base de uma relação comunicacional, uma vez que esta pressupõe a apreensão conjunta dos fenômenos discursivos, amparada em laços afetivos e cognitivos. Fica evidente que essa concepção de comunicação não se contenta com a ideia de um simples tornar algo comum a alguém, ou com a suficiência a priori do principio de interação, colaboração ou conectividade da rede.

\section{Estetização da imagem versus estética da comunicação}

0 aspecto da estetização das mídias tem sido postulado por autores de diversas correntes, tanto aqueles que se dedicam a estudar as estratégias discursivas, quanto os que preconizam os procedimentos sistemáticos da economia da atenção e dos afetos. Muniz Sodré (2006, p. 123) refere-se, por exemplo, à potencialização dos agentes sensíveis nas mediações simbólicas, em especial no ambiente das mídias atuais, mas chama a atenção para o seu uso domesticado, que uniformiza as emoções em atitudes e valores coletivos às vezes irracionais. Nos anos 80, Debord (1997) já havia descrito esse panorama, quando retomava os conceitos de poder concentrado e difuso para convergi-los na forma do espetáculo integrado, em cujo domínio as mídias exerceriam um papel fundamental na configuração espetacular, justificadora de valores classistas. Nessas perspectivas, o estético está sendo apropriado em sua condição estésica, fundamental para o sentir comum do estado de compartilhamento intersubjetivo acima aventado.
A diferença consistiria no efeito desse tipo de experiência para o movimento compreensivo.

No que toca a imagem, o fenômeno da estetização deve ser abordado não apenas de uma perspectiva formal, mas sobretudo histórico-política, no quadro geral dos fenômenos de estetização das mercadorias, de que pode constituir aspecto particular. 0 mercado temse aprimorado em ações inimagináveis de persuasão pelo sensível, desde 0 velho recurso às embalagens, que se tornam o motor do desejo de compra, até estratégias atuais mais sofisticadas. É uma evidência de que 0 valor de uso não só não interessa, como se converte em um problema resolvível no âmbito da apresentação material da mercadoria (HAUG, 1997, p. 54-55). Por analogia, é possível afirmar que também a imagem pode vir a ter 0 seu plano da expressão privilegiado por dispositivos técnicos atraentes em detrimento de uma densidade dos conteúdos veiculados. Funcionam como "stopers", na citação que Wolfgang Haug faz da linguagem publicitária (nota 60, p. 142), para a retenção do olhar e para a cosmetização de um todo (em qualquer superfície: impressa, televisiva ou do ciberespaço). Mesmo quando agenciam experiências pregnantes, são imediatamente sobre-determinadas por outros conteúdos destinados a re-inscrever o leitor-espectador no contexto do consumo. Por isso, o uso de imagens naturalistas, como representações do real, é hegemônico nas mídias. É aí que o conceito de documental emerge, como seu ambiente natural, 
onde "suas regras se fazem transparentes" (LED0, 1998, p. 13). No jornalismo, o fato se evidencia com a fotografia: a confiança na câmera para o registro dos fenômenos determina tanto o seu uso intenso com o aprimoramento técnico dos aparelhos como a supremacia para fins documentais, a despeito dos modos como ela pode se relacionar com as matérias verbais, uma vez que o jornalismo passa a usá-la cada vez mais dentro desse espírito de uma estetização generalizada da própria mídia como mercadoria.

A divisão que vai se instalando entre fotojornalismo e documentarismo, nos seus sentidos tradicionais, tem como um dos móveis a maneira diferenciada de enxergar essa relação entre homem e máquina, iniciando-se com a fotografia e perpetuando-se com as tecnologias que a sucedem. Com a introdução da TV no mercado e a sua presença cotidiana nas vidas das pessoas, os jornais impressos começam a mudar seus padrões visuais, recorrendo à força apelativa das fotografias. As primeiras páginas, em especial, assumem um padrão visual multifacetado e colorido nos moldes da apresentação televisiva. Suas imagens são incorporadas ao jornal, como mostras de atualização e agilização das notícias, enquanto a TV se utiliza, mais esporadicamente, de fotos para trazer o que lhe parece ainda específico desse meio: a garantia da documentaridade e da dramaticidade de um fato.

Nesse percurso, o jornalismo assenta seu padrão tecno-estético no uso de imagem em cores, com resolução capaz de manter legibilidade no papel-jornal ${ }^{3}$, de contornos bem definidos e de clara vinculação com a matéria verbal diante da qual opera como chamariz. Do ponto de vista figurativo, a preferência tem recaído, salvo em ocasiões excepcionais, sobre 0 retrato, principalmente do gênero "people" que transita das revistas e da TV para o jornal diário, onde se traveste de uma aparente função política. Nessa ambiência, a fotografia é capaz ainda de portar algumas máscaras: de foto oficial, cosmetizada, passando pelo aspecto lúdico do flagrante delito - como instantâneo de situações ou de gestos ridículos de políticos e celebridades capturados pela câmera - até imagens despidas de artifícios fotográficos, que ocupam sobretudo os espaços menos nobres das colunas policiais (LANDOWSKI, 2007, p. 93), onde aparecem como "fiel retrato" dos sujeitos "à margem" (no duplo sentido) da sociedade. Em todos esses casos, o fazer ver do fotógrafo opera por mecanismos distintos de encenação, "jogando

"0 repórter fotográfico faz a cobertura dos acontecimentos atuais de uma maneira simples e direta. É seu trabalho conseguir fotos nítidas e audaciosas, que conservem sua mensagem apesar da má qualidade de reprodução dos jornais” (DONDIS, 2003, p. 214). Busca-se usar as imagens em função de sua aparência estetizante, como atrativo da atenção. Nesse caso, o papel de sua matéria expressiva, ou de seu plano de expressão, é atrair pelas cores, tons, contrastes, propiciando a sensação de uma leitura visual mais apressada e às vezes substitutiva da mensagem verbal. Em outros termos, o plástico serve de mero "suporte" ao figurativo, que assume a feição do representacional. Essa aparência de que se dota a fotografia, como efeito de realidade, repercute numa espécie de reificação da imagem, à qual não se atribui senão a funcionalidade ilustrativa de uma história visual dos fatos históricos e sociais. 
luz" sobre pessoas que, graças à sua visibilidade, tornam-se notícias enquanto ocuparem o espaço midiático. Convém esclarecer que a esse quererver do fotógrafo coaduna ou contrapõe-se um querer-ser-visto de alguns - que mobilizam, eles também, dispositivos de auto-encenação para se tornarem públicos, muitas vezes manifestado sob um jogo de simulações - e o querer-não-servisto de outros - do mesmo modo pautado por múltiplos artíficios de invisibilidade (CAETANO; LEMOS, 2007). De tais encontros derivam relações de sentido e de presença complexos movidos pelo cruzamento dos regimes do ver.

Seria ingênuo, no entanto, apregoar um fosso entre a fotografia de imprensa e aquela resultante dos projetos documentais. Pontilham as páginas dos jornais, ainda que em atmosfera rarefeita, uma ou outra fotografia cujo efeito estetizante não reside apenas na função "stoper" para chamada ao verbal. São aquelas que consideramos pregnantes pela capacidade de sintetizar imageticamente, por acionamentos sensíveis e cognitivos, a ambivalência de uma informação. Do mesmo modo, nem toda imagem documental, ainda que plena de boas intenções, chega a ter resultados satisfatórios para a ação persuasiva. Um olhar extraído da sociologia da imagem pode constituir bom exemplo, com base na leitura que o sociólogo José de Souza Martins (2008, p. 133-171) faz da famosa fotografia de Sebastião Salgado que registra a tomada da Fazenda Giacometti, no norte do Paraná, pelos manifestantes do Movimento dos Sem Terra
(MST). 0 problema, nos diz Martins, é que a foto celebra a consumação e não o processo da tomada. Essa sensação decorre do fato de que 0 fotógrafo adentra a fazenda antes dos integrantes do MST e nos lembra que se coloca ali, possivelmente de um melhor ponto de vista no cálculo de uma tomada da extensão da "fila" de seus participantes, como a esperar o momento decisivo da entrada (p. 134). Traduzindo em linguagem metafórica o que se nos afigura como uma escolha enunciativa, a invasão antecipada do, e pelo, fotógrafo retira o impacto da intervenção humana na luta pelos seus direitos.

Além disso, na fase atual do jornalismo participativo, uma foto, mesmo sem propósito documental, pode converter-se na vedete de uma cobertura pelo simples fato de representar a única imagem capturada no calor da hora, portanto eficaz em sua funcionalidade simbólica para presentificar certo acontecimento. Tratase de prevalências e não de singularidades, dependentes de uma série de fatores, de natureza econômica, tecnológica e estilística; nesse último caso, de modos de vida e de presença (portanto de sentido) no mundo.

Mais frequentemente, no entanto, os projetos que envolvem a criação de imagens fotojornalísticas e documentais, no quadro total das condições de produção em que as mesmas se constroem, constituem escolhas discursivas diferenciadas. Visando a gerar impressões de um pluralismo de ideias que atendam aos diversos segmentos, tais 
distinções podem ser convocadas e ao mesmo tempo neutralizadas no espaço dos próprios meios de veiculação massiva. Tendo em vista que as imagens referenciam as matérias verbais de acordo com 0 tom da seção em que se inserem, acabam contaminando-se de um valor expressivo que é o de parecer ilustrar adequadamente os fragmentos da realidade configurados nos seus diversos cadernos. Suas diferenças podem então ser apagadas em prol do aspecto uniformizador da mídia que determina o quê e como documentar. Um exemplo pode ser encontrado na Folha de São Paulo de 29/06/2008, que traz no caderno Dinheiro (p. B8) e na primeira página da Ilustrada, a temática da fome e da insuficiência do Bolsa Família, benefício social do governo brasileiro instituído pelo presidente Lula. As implicações comunicacionais do modo de relatar 0 assunto pela imagem divergem. No caderno Dinheiro, a pauta é mostrar a defasagem do benefício, em face do aumento da inflação e das famílias, com o nascimento de filhos de jovens beneficiários. A informação da matéria verbal é ilustrada por fotos coloridas e atraentes, infográficos e cópia da redação de uma criança, que atuam como fortes apelos para o olhar graças aos contrastes de iluminação, cromáticos e outros aspectos técnicos que, aliados aos títulos e legendas, permitem à página expor-se como um todo de sentido adequado ao princípio da atenção e da fixação da mídia sobre si mesma.

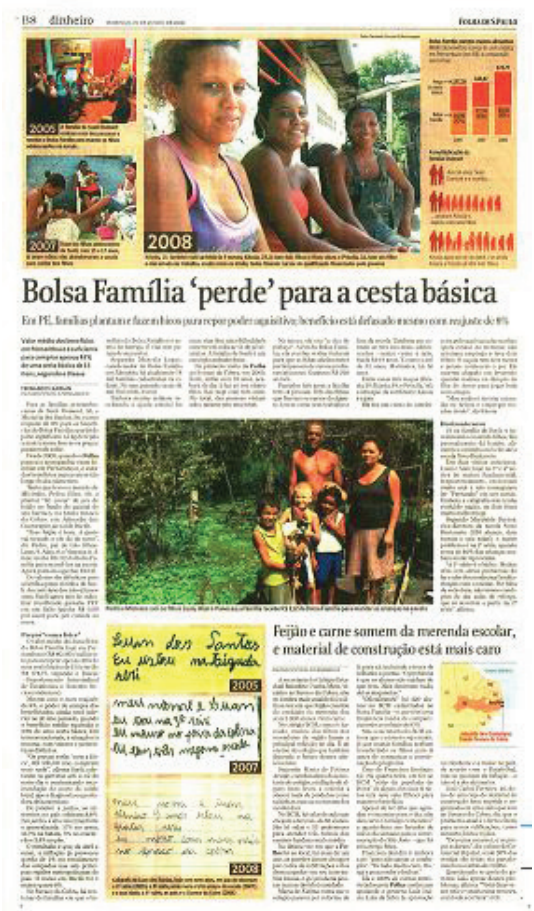

Figura 1 - Matéria sobre Benefício Bolsa Família

Fonte: Folha de São Paulo, caderno Dinheiro, p. B8, fotos de Fernando Canzian-Folha Imagem. 
0 olhar, primeiro numa tomada geral, circula a partir das fotos maiores, prescruta as fotosdetalhes, confere o infográfico e se emociona com os trechos mal redigidos do texto da criança. Nesse contexto, as fotos criam o apoio necessário tanto de atrativo quanto de resumo visual do que se pretende noticiar. Mais próximas dos recursos da fotografia publicitária, elas atravessam a discussão dos assuntos socioeconômicos, ao mesmo tempo que estruturam a informação segundo os parâmetros de uma publicidade generalizada.

No caderno Ilustrada, o assunto Bolsa Família volta à tona, desta vez para justificar os motivos do cineasta José Padilha para a execução de seu documentário, que retrata a luta de três famílias no Ceará contra a miséria e a fome, acompanhadas em sua rotina durante 30 dias, duas das quais suprindo a falta de alimentos a dar às crianças, nesse período, com mamadeiras de água com açúcar. A insuficiência do benefício é polemizada e 0 texto igualmente ilustrado por várias fotos.

Ao contrário da matéria econômica, por outro lado, as imagens são em preto e branco, afirmando uma tradição da fotografia documental (preferida nesse meio como portadora de maior força expressiva para a abstração). 0 recurso ao $\mathrm{p} / \mathrm{b}$ favorece 0 trabalho com luz e sombras, meios-tons e granulações expostas, retirando da fotografia aquilo que se consagrou como

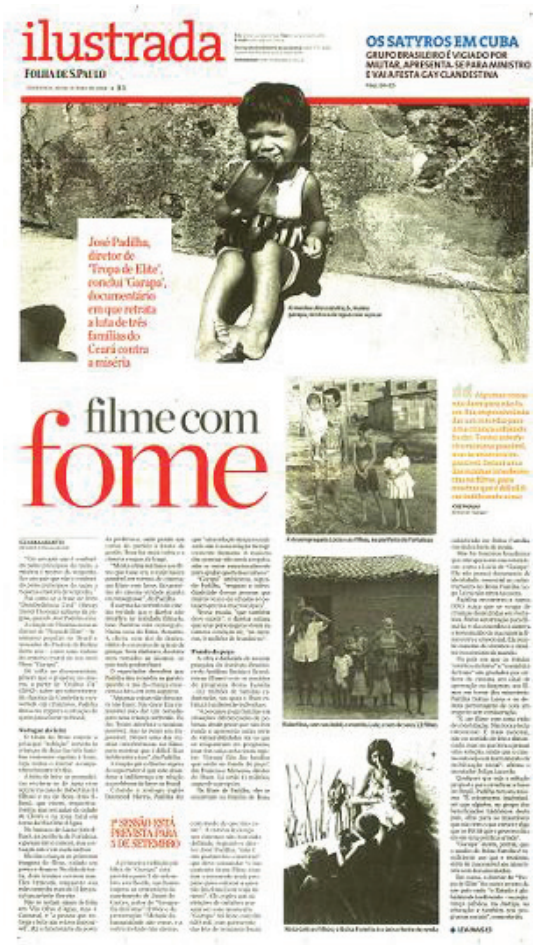

Figura 2. Matéria sobre filme Garapa de José Padilha. 
sendo próprio de seu meio, ou seja, a linearidade da imagem dada pelos contornos claros, a delimitação precisa dos objetos e o contraste acentuado. Linearidade e pictorialidade são as duas tendências que, segundo Wölfflin (2006, p. 25-40), se tornaram padrões de figuração na história das imagens. Delineiam, desse modo, uma história do olhar e das imagens como componentes das relações culturais e comunicacionais. Essas fotos revelam, portanto, na contramão do processo predominante no jornalismo, uma direção para o movimento desestabilizador do representacional subjacente ao estilo linear. Esse movimento a meio caminho entre 0 traço naturalista e 0 abstrato é que mantém a figuralidade necessária ao padrão documental. 0 leitor já é convocado, de imediato, a colocar-se num outro universo de leitura que é aquele da arte, principalmente porque as fotos não se reportam em primeira instância a uma realidade, mas ao filme. Servem, na verdade, para a divulgação do filme, da autoria de Alexandre Lima. Assim como na seção Dinheiro, o recurso ao sensível se mostra, mas as estratégias de seu aproveitamento para a economia simbólica do discurso variam, na medida em que as fotos da Ilustrada, além de chamariz da atenção (e recurso de divulgação), permitem recuperar a ambiência do discurso de que se fala. É assim que a motivação para 0 estético predomina na mídia massiva, como uma das formas de estetização da mercadoria e a favor, direta ou indiretamente, do veio publicitário. 0 jornal lhe outorga um papel claro no conjunto das informações, distinguindo a ilustração do que compete à discussão da cultura em oposição aos outros temas da vida.

0 problema da fome emerge novamente, mas com nova indumentária figurativa - no quadro da discussão econômica as imagens parecem ilustrar objetivamente a matéria verbal, além de comporem importante quesito para o design da página; na divulgação do documentário, revelam seu teor conceitual, como a anunciar a transição para um novo território, o da "arte engajada". Paradoxalmente, essa inserção retira o peso conotativo da imagem por remetê-la mais a uma atmosfera de exposição dos fatos culturais do que da fome como fato socioeconômico propriamente dito, situando-a em geral num "estrato separado do mundo exterior" (BAEZA, 2001, p. 48).

\section{Imagens em rotação}

Sem questionar o cenário favorável vislumbrado pela proliferação das redes de notícias de fonte aberta, uma questão - que também está na nascente do debate entre mídia e poder volta à cena. Ao mesmo tempo que permitem a dilatação da fonte informativa, desautorizando o controle elitista e corporativo da pauta midiática, essas novas práticas podem se compor como um mosaico de opiniões infundadas, muitas vezes deglutidas da mídia tradicional, limitando-se, de acordo com a responsável pelo blog de notícias americano HuffPost, Arianna Huffington, a "cuspir" as informações dos 
cotidianos tradicionais. ${ }^{4}$ Segundo depoimentos dos responsáveis pelo site, a primeira página ainda está submetida a um procedimento de triagem, que visa a atrair o filão publicitário, enquanto as secundárias cumprem o papel transformador do blog, que é o de gerar uma atividade compartilhada livre, comprovando a afirmação de Baeza a respeito da mídia impressa (2001, p. 56), de que a publicidade continua a determinar e legitimar o que é credível e confiável em termos de notícia.

De seu lado, impulsionados pela concorrência da TV e da web, os jornais impressos têm criado mecanismos estratégicos de aceleração do tempo de consumo da notícia. Um processo simbiótico se instaura, de alimentação das mídias organizadas pelos blogs e sites particulares, e de retroalimentação destes, simultaneamente, pelo conteúdo que circula nas grandes mídias.

As imagens jornalísticas se inscrevem nesse contexto em suas formas mais tradicionais e cíclicas convocadas a exprimir rápida e eficientemente seu valor testemunhal.

Quando se aborda 0 universo da cibercultura, dois aspectos interligados podem ser levados em conta para nossa reflexão. 0 primeiro diz respeito ao fenômeno atual da proliferação de imagens, intensificado com os dispositivos cada vez mais eficientes de transmissão, com a introdução da banda larga e aparatos móveis, além da criação de mídias independentes e programas livres. 0 segundo concerne à afirmação de uma forma de interatividade efetiva, como inerente ao ambiente virtual. Nesse meio, parecem neutralizar-se as distinções surgidas no âmbito do impresso, uma vez que, embora configurando nichos, o espaço é agora convergente e possibilita navegabilidade por vários sítios, do que resultam associações de informações e imagens de todo tipo, capazes de colocar em xeque dados veiculados pelas grandes mídias. Tais condições são consideradas propícias à crise de credibilidade da imagem documental em sentido corrente e da crise da cultura documental como um todo, o que poderia fazer supor a possibilidade de compreensão e utilização da imagem na sua qualidade de linguagem, ou seja, construção simbólica. Paradoxalmente, é nessa atmosfera que se vai-se fortalecendo uma tendência dominante de privilegiar imagens como representações do real, tão mais realistas quanto maior for a evidência de suas limitações, pois revelam o fato capturado no calor da hora. Como uma volta ao velho jornalismo documental, é dependente da confiança na câmera e presença in situ para provar o que se relata, ao mesmo passo que desvela 0 seu caráter contraditório: a denúncia de um desmantelamento da representação pelo digital se faz acompanhar da ânsia em mostrar o que "realmente aconteceu". Na perspectiva talvez demasiado excessiva, porém crítica, de Ledo, 
Desaparece el fotoperiodismo y la fotografía documental porque se desprofesionaliza el universo de los medios con la intención de que cada uno de nosotros nos convirtamos en nuestro propio editor. Es la filosofía de la interacción, de la conectividad en tiempo real, un mundo de visionarios que en poco tiempo no podrá salir de su habitación porque será, al contrario de Gregor Samsa, quien no reconozca el mundo exterior (1998, p. 28).

Ao recorrer à metáfora da metamorfose do personagem kafkiano, a autora afirma que 0 problema não reside tanto na perda de credibilidade dos velhos axiomas que outorgavam à foto capacidade informativa, $\mathrm{e}$ sim na perda de capacidade para nos transmitir elementos de compreensão e de sensações sobre 0 real (p. 28-29).

0 compartilhamento alegado nesses ambientes é diferente daquele apresentado pelo documental como um projeto expressivo (em qualquer espaço midiático), embora possa agir pelo sensível. A par de figuras de grande efeito técnico, emergem com vigor essas imagens-protagonistas a ganhar força no conjunto das manobras discursivas invocadas para uma leitura documental. São consideradas eficazes na ação de fazer sentir, ou de criar sensações de um sentir comum, pelo efeito de verdade que uma "boa imagem" pode provocar. Não deixa de haver certa ironia nessa construção coletiva, agora elaborada a várias mãos e identificada em suas bases afetivas, mas ainda estribada na hegemonia do efeito de verdade do uso convencional das imagens. Ironia que aparece bem formulada na visão circular de que a imagem numérica persegue 0 valor de realidade da imagem analógica, "porque la imagen numérica, más performática, pueda fagocitar a aquélla y devolvernos otra imagen que parece analógica y que nosotros, indefectiblemente, descifraremos como realidad." (LEDO, 1998, p. 41)

Projetos empenhados numa espécie de regeneração do olhar que permitam re-ver 0 mundo, como diria o pintor René Magritte, no domínio do documentarismo contemporâneo, existem, agora beneficiando-se das vantagens dos aparatos digitais e do mundo virtual, mas continuam restritos a um pequeno público ou engolfam-se no abismo de tantas outras imagens, entre as quais perdem toda a referência. Com o exposto, queremos asseverar que a mudança radical das condições técnicotecnológicas em que ocorrem as trocas simbólicas, no caso específico da informação pela imagem, não é prerrogativa necessária para a constituição da comunicação como um fenômeno estético, ou seja, em sua potencialidade compreensiva e transformadora.

\section{Fendas da imagem}

A importância da definição do ser em termos históricos, efetivada pelas obras posteriores de Heidegger, reside no fato de que ele 0 revela não só como um ser que se abre para as coisas do mundo, mas também porque 0 constitui por meio de suas ações e decisões. É verdade que 0 autor explora essa intervenção na obra de arte, referida como o locus da experiência estética, 
embora pontue algumas de suas manifestações em domínios externos ao campo. Vamos tomar essa experiência no seu sentido alargado, fora dos limites da arte, e aproveitar de Heidegger a ideia de brecha que ela institui entre a possibilidade da descoberta e a incompletude do que há ainda a descobrir-se (HEIDEGGER, 2008, p. 38-44). Ela não apenas manifesta uma totalidade de significados do mundo, baseada no ser comum, mas a produz naquilo que na experiência se retrai e se expõe na porosidade dos discursos. Com base nesse princípio, fragiliza-se a discussão da permeabilidade do documental tanto ao real, quanto ao estético, preferindo-se colocá-la sobre outro esteio: 0 da potencialidade de seu agir nas condições estéticas da comunicação.

\section{Referências}

CAETANO, Kati, LEMOS, Anuschka Reichmann. À margem do olhar, à margem da imagem: regimes de visibilidade na fotografia documental. Razón y palabra . México, vol. 22, p. 1-18, set. 2007.

BAEZA, Pepe. Por una función crítica de la

fotografía de prensa. Barcelona: Gustavo Gili, 2001.

DEBORD, Guy. A sociedade do espetáculo. Rio de Janeiro, Contraponto, 1997.

DONDIS, Donis. Sintaxe da linguagem visual. São

Paulo: Martins Fontes, 2003.

FLOCH, Jean-Marie. Les formes de l'empreinte: Brandt, Cartier-Bresson, Doisneau, Stieglitz, Strand. Périgueux: Pierre Fanlac, 1986.

FREUND, Gisele. La fotografía como documento social Barcelona: Gustavo Gili, 2002.
GREIMAS, Algirdas-Julien. De l'imperfection.

Périgueux: Pierre Fanlac, 1987.

HAUG, Wolfgang Fritz. Crítica da estética da mercadoria. São Paulo: Unesp, 1997.

HEIDEGGER, Martin. A origem da obra de arte. Lisboa: Edições 70, 2008.

LANDOWSKI, Eric. Flagrants délits et portraits. In : SEMPRINI, A. (org.) Analyser la communication II: regards sociosémiotiques. Paris : L’Harmattan, 2007. p. $89-126$.

LEDO, Margarita. Documentalismo fotográfico: éxodos e identidad. Madrid: Cátedra, 1998.

MARTINS, José de Souza. A epifania dos pobres da terra. In: MAMMI, L. \& SCHWARCZ, L. M. (orgs.). 8 X Fotografia: ensaios. São Paulo: Companhia das Letras, 2008. p. 133-171.

SODRÉ, Muniz. As estratégias sensíveis: afeto, mídia e política. Petrópolis: Vozes, 2006.

SOUSA, Jorge Pedro. Uma história crítica do fotojornalismo ocidental. Chapecó: Grifos, 2000. Fotojornalismo: introdução à história, às técnicas e à linguagem da fotografia na imprensa. Florianópolis: Letras Contemporâneas, 2004.

VATTIMO, Gianni. Introdução a Heidegger. Lisboa: Edições 70, 1989.

WÖLFFLIN, Heinrich. Conceitos fundamentais da história da arte. São Paulo: Martins Fontes, 2006. 


\begin{tabular}{|c|c|}
\hline $\begin{array}{l}\text { Documental practices and aesthetics } \\
\text { in the tradition of 'separating the } \\
\text { wheat from the chaff' }\end{array}$ & $\begin{array}{l}\text { Prácticas documentales } \\
\text { y estética en la tradición de } \\
\text { 'separar el trigo de la paja' }\end{array}$ \\
\hline $\begin{array}{l}\text { Abstract } \\
\text { Centered in the discussion of visual image, the } \\
\text { text approaches its uses with informative function } \\
\text { and the ramifications initially generated by } \\
\text { an established opposition in the media realm } \\
\text { between documentation and aesthetics. Based on } \\
\text { the postulate that the images can constitute an } \\
\text { important element to a communication aesthetics, } \\
\text { the principle of the work is the printed journalism } \\
\text { and it extends to some collaborative forms from } \\
\text { cyberspace in the production of visual matters, } \\
\text { dimensioning again the affirmative of a media } \\
\text { aestheticization, supported, in these contexts, by } \\
\text { its technical artifices and affective dimension of } \\
\text { interactions. } \\
\text { Keywords } \\
\text { Documentarism. Aesthetics. Reality effect. Image } \\
\text { politics. Informative image. }\end{array}$ & $\begin{array}{l}\text { Resumen } \\
\text { Centrado en la discusión de la imagen visual, } \\
\text { el texto descorre sobre sus utilizaciones con } \\
\text { función informativa y los desdoblamientos } \\
\text { generados inicialmente por una oposición } \\
\text { establecida en el dominio de los medios de } \\
\text { comunicación entre documentación y estética. } \\
\text { Con base en el postulado de que las imágenes } \\
\text { pueden constituir elementos importantes para } \\
\text { una estética de la comunicación, el trabajo tiene } \\
\text { como punto de partida el periodismo impreso y } \\
\text { se extiende a ciertas formas colaborativas del } \\
\text { ciberespacio en la producción de materiales } \\
\text { visuales, redimensionando a la afirmativa de una } \\
\text { estetización de los media, amparada, en esos } \\
\text { contextos, por sus artificios técnicos y dimensión } \\
\text { afectiva de las interacciones. } \\
\text { Palabras clave } \\
\text { Documentarismo. Estética. Efecto de realidad. } \\
\text { Políticas de la imagen. Imagen informativa. }\end{array}$ \\
\hline
\end{tabular}




\section{Expediente}

A revista E-Compós é a publicação científica em formato eletrônico da Associação Nacional dos Programas de Pós-Graduação em Comunicação (Compós). Lançada em 2004, tem como principal finalidade difundir a produção acadêmica de pesquisadores da área de Comunicação, inseridos em instituições do Brasil e do exterior.
E-COMPÓS I www.e-compos.org.br I E-ISSN 1808-2599

Revista da Associação Nacional dos Programas de Pós-Graduação em Comunicação. Brasília, v.12, n.2, maio/ago. 2009

A identificação das edições, a partir de 2008 passa a ser volume anual com três números.

\section{CONSELHO EDITORIAL}

\section{Afonso Albuquerque}

Universidade Federal Fluminense, Brasil

Alberto Carlos Augusto Klein

Universidade Estadual de Londrina, Brasi

Alex Fernando Teixeira Primo

Universidade Federal do Rio Grande do Sul, Brasi

\section{Alfredo Vizeu}

Universidade Federal de Pernambuco, Brasil

Ana Carolina Damboriarena Escosteguy

Pontifícia Universidade Católica do Rio Grande do Sul, Bras

Ana Silvia Lopes Davi Médola

Universidade Estadual Paulista, Brasil

André Luiz Martins Lemos

Universidade Federal da Bahia, Brasil

Ângela Freire Prysthon

Universidade Federal de Pernambuco, Brasil

Antônio Fausto Neto

Universidade do Vale do Rio dos Sinos, Brasil

Antonio Carlos Hohlfeldt

Pontifícia Universidade Católica do Rio Grande do Sul, Brasil

Arlindo Ribeiro Machado

Universidade de São Paulo, Brasil

César Geraldo Guimarães

Universidade Federal de Minas Gerais, Brasil

Cristiane Freitas Gutfreind

Pontifícia Universidade Católica do Rio Grande do Sul, Brasil

Denilson Lopes

Universidade Federal do Rio de Janeiro, Brasil

Eduardo Peñuela Cañizal

Universidade Paulista, Brasi

Erick Felinto de Oliveira

Universidade do Estado do Rio de Janeiro, Brasil

Francisco Menezes Martins

Universidade Tuiuti do Paraná, Brasil

Gelson Santana

Universidade Anhembi/Morumbi, Brasi

Hector Ospina

Universidad de Manizales, Colômbia

leda Tucherman

Universidade Federal do Rio de Janeiro, Brasil

Itania Maria Mota Gomes

Universidade Federal da Bahia, Brasil

Janice Caiafa

Universidade Federal do Rio de Janeiro, Brasil

Jeder Silveira Janotti Junior

Universidade Federal da Bahia, Brasil

\section{João Freire Filho}

Universidade Federal do Rio de Janeiro, Brasil

John DH Downing

University of Texas at Austin, Estados Unidos

José Luiz Aidar Prado

Pontifícia Universidade Católica de São Paulo, Brasil

José Luiz Warren Jardim Gomes Braga

Universidade do Vale do Rio dos Sinos, Brasil

Juremir Machado da Silva

Pontifícia Universidade Católica do Rio Grande do Sul, Brasil

Lorraine Leu

University of Bristol, Grã-Bretanha

Luiz Claudio Martino

Universidade de Brasília, Brasil

Maria Immacolata Vassallo de Lopes

Universidade de São Paulo, Brasil

Maria Lucia Santaella

Pontifícia Universidade Católica de São Paulo, Brasil

Mauro Pereira Porto

Tulane University, Estados Unidos

Muniz Sodre de Araujo Cabral

Universidade Federal do Rio de Janeiro, Brasil

Nilda Aparecida Jacks

Universidade Federal do Rio Grande do Sul, Brasil

Paulo Roberto Gibaldi Vaz

Universidade Federal do Rio de Janeiro, Brasil

Renato Cordeiro Gomes

Pontifícia Universidade Católica do Rio de Janeiro, Brasil

Ronaldo George Hela

Universidade do Estado do Rio de Janeiro, Brasil

Rosana de Lima Soares

Universidade de São Paulo, Brasil

Rossana Reguillo

Instituto Tecnológico y de Estudios Superiores do Occidente, México

Rousiley Celi Moreira Maia

Universidade Federal de Minas Gerais, Brasil

Sebastião Carlos de Morais Squirra

Universidade Metodista de São Paulo, Brasil

Simone Maria Andrade Pereira de Sá

Universidade Federal Fluminense, Brasil

Suzete Venturelli

Universidade de Brasília, Brasil

Valério Cruz Brittos

Universidade do Vale do Rio dos Sinos, Brasil

Veneza Mayora Ronsini

Universidade Federal de Santa Maria, Brasil

Vera Regina Veiga França

Universidade Federal de Minas Gerais, Brasil
COMISSÃO EDITORIAL

Ana Gruszynski I Universidade Federal do Rio Grande do Sul, Brasil Felipe da Costa Trotta I Universidade Federal de Pernambuco, Brasil Rose Melo Rocha I Escola Superior de Propaganda e Marketing, Brasil

\section{CONSULTORES AD HOC}

Aníbal Francisco Alves Bragança I Universidade Federal Fluminense, Brasil Benjamim Picado I Universidade Federal da Bahia, Brasil

Carlos Eduardo Franciscato I Universidade Federal de Sergipe, Brasi

Christa Liselote Berger I Universidade Vale do Rio dos Sinos, Brasil

Gisela Castro I Escola Superior de Propaganda e Marketing, Brasil

Luciana Pellin Mielniczuk I Universidade Federal de Santa Maria, Brasi

Marcia Benetti I Universidade Federal do Rio Grande do Sul, Brasil

Paulo Cunha Carneiro Filho I Universidade Federal de Pernambuco, Brasil

Raquel Recuero I Universidade Católica de Pelotas, Brasil

REVISÃO DE TEXTO E TRADUÇÃO I Everton Cardoso

EDITORAÇÃO ELETRÔNICA I Raquel Castedo
COMPÓS I www.compos.org.br

Associação Nacional dos Programas de Pós-Graduação em Comunicação

Presidente

Itania Maria Mota Gomes

Universidade Federal da Bahia, Brasil

itania@ufba.br

Vice-presidente

Julio Pinto

Pontifícia Universidade Católica de Minas Gerais, Brasil

juliopinto@pucminas.br

Secretária-Geral

Ana Carolina Escosteguy

Pontifícia Universidade Católica do Rio Grande do Sul, Brasil

carolad@pucrs.br 